\title{
HUBUNGAN ANTARA SELF-EFFICACY DENGAN STRES KERJA PADA GURU SEKOLAH DASAR (SD) NEGERI DI KECAMATAN MENGANTI
}

\author{
Fitria Lailatul Ula ${ }^{1}$, Nadhirotul Laily ${ }^{2}$ \\ Universitas Muhammadiyah Gresik
}

\begin{abstract}
Abstrak
Tujuan dalam penelitian ini adalah untuk mengetahui hubungan antara self-efficacy dengan stres kerja pada guru SD Negeri di Kecamatan Menganti. Peneliti menggunakan teknik cluster sampling sebanyak 186 Guru SD di Kecamatan Menganti. Metode pengumpulan data dalam penelitian ini menggunakan skala self-efficacy dan skala stres kerja pada Guru. Uji validitas skala ini menggunakan validitas isi. Sedangkan uji reliabilitas dalam penelitian ini menggunakan koefisien Alpha Cronbach dengan bantuan program SPSS 16.0 for Windows. Teknik analisis data dalam penelitian ini menggunakan Korelasi Sperman Rank. Hasil uji korelasi menunjukkan $\mathrm{r}_{\mathrm{ho}}=-0,127$ dengan taraf signifikan 0,288 ( $\mathrm{p}>0,05$ ). Hal ini menunjukkan bahwa $\mathrm{H} 0$ diterima dan Ha ditolak. Berdasarkan hasil penelitian dapat disimpulkan bahwa tidak ada hubungan antara selfefficacy dengan stres kerja pada guru SD Negeri di Kecamatan Menganti.
\end{abstract}

Kata Kunci: Stres Kerja, Self-Efficacy, Guru SD

\begin{abstract}
The purpose of this research is to find relationship between self-efficacy with job stress on teacher of public elementary school in subdistrict Menganti. Researchers used cluster sampling technique as many as 186 teacher of elementary school in subdistrict Menganti. The accumulation data metode in this study using scale self-efficacy and scale job stress on teacher. Validity test this scale using content validity. While reliability test in this study using coefficient Alpha Cronbach with help SPSS 16.0 for windows program. Data analysis technique in this study using is sperman rank correlation. The result correlation test show that rho $=0,127$, with signifikan level 0,288 ( $p>0,05)$. This shows that HO is accepted and Ha is rejected. Based on the results of the study can be concluded that there is no relationship between self-efficacy with job stress in public elementary school teachers in subdistrict Menganti.
\end{abstract}

Keywords: Job Stress, Self-Efficacy, Teacher of Elementary School.

\footnotetext{
1email: fitria.lailatulula96@gmail.com

Fakultas Psikologi Universitas Muhammadiyah Gresik

Randuagung, Gresik, Jawa Timur
}

Hubungan Antara Self-Efficacy Dengan Stres Kerja Pada Guru Sekolah Dasar (SD) Negeri Di 


\section{Pendahuluan}

Sekolah dasar merupakan salah satu jenjang pendidikan formal di Indonesia berdasarkan usia dan kemampuan peserta didik. Dalam pelaksanaannya, siswa-siswi diberikan dengan sejumlah materi atau pelajaran yang harus dikuasai sebagai pendidikan dasar anak didik. Sebagai makhluk sosial, yang dilimpahkan akal, pikiran, rasa dan karsa oleh Tuhan serta membutuhkan pendidikan sebagai bekal dalam upaya membantu pengetahuan dalam menghadapi permasalahan hidup di masa yang akan mendatang. Oleh karena itu, sangat dibutuhkan seorang guru yang berkualitas dan berkompeten sebagai pendidik yang profesional, kreatif dan menyenangkan. Guru berperan sebagai pendidik dan pengajar, maka perlu untuk memiliki kemampuan yang dapat dimiliki peserta didik melalui kegiatan belajar mengajar.

Dalam hal profesional seorang guru harus menguasai keterampilan mengajar dalam membuka dan menutup pelajaran, bertanya, memberi penguat, dan mengadakan berbagai macam kegiatan dalam mengajar. Wardani (2014:7) menyatakan bahwa kompetensi yang harus dimiliki oleh Guru yaitu: (1) memahami karakteristik siswa, (2) memahami latar belakang keluarga siswa, (3) memahami cara belajar siswa, (4) mengembangkan potensi siswa, (5) menguasai materi pada setiap mata pelajaran siswa, (6) mampu merancang pembelajaran yang mendidik, (7) mampu melaksanakan pembelajaran yang mendidik, (8) mampu menilai proses dan hasil pembelajaran siswa dan (9) mampu meningkatkan kualitas pembelajaran melalui penelitian tindakan kelas.

Guru yang berkompeten akan lebih mampu untuk menciptakan suasana belajar secara efektif dan menyenangkan serta mampu dalam mengolah kelasnya sehingga siswa dapat belajar secara optimal (Saragih, 2008:23-34). Oleh karena itu, untuk menjadi guru yang berkompeten harus memiliki self-efficacy yang tinggi. Selain memiliki self-efficacy yang tinggi, seorang guru juga harus memiliki pengalaman yang berkaitan dengan timbal balik dari atasan terhadap pekerjaan yang telah dilakukan secara berulang-ulang, pengalaman atas keberhasilan guru yang memberikan pengaruh besar terhadap self-efficacy, pengamatan atau penilaian terhadap orang lain atas keberhasilan yang dicapainya dengan kemampuan yang sama dalam menjalankan tugasnya. Arahan, nasihat, dan bimbingan dari atasan dapat meningkatkan keyakinan yang terkait dengan kemampuan yang dimilikinya (Gufron \& Risnawita, 2014:78). Hal ini akan membantu guru dalam mencapai tujuan yang diinginkannya.

Dalam menjalankan tugasnya seorang guru juga bisa mengalami berbagai hambatan seperti beban kerja tinggi. Apabila seorang guru tidak dapat mengatasi hambatan-hambatan tersebut, ia dapat mengalami stres. Robbin (2017:434) menyatakan bahwa stres merupakan proses psikologis yang terjadi sebagai tanggapan terhadap tekanan lingkungan yang tidak menyenangkan. 
Peneliti melalui wawancara pada guru SD di Kecamatan Menganti yang mengatakan bahwa penyebab stres dalam mengajar di SD yaitu pada sistem penilaian kurikulum 2013, pembuatan RPP, menjalankan tugas yang berbeda dalam satu lembaga selain mengajar anak didiknya, adanya persaingan antar guru dan jadwal pembelajaran yang tidak konsisten sehingga menyebabkan kerja sama yang kurang optimal, kurangnya komunikasi antara kepala sekolah dan guru, dan kurangnya waktu untuk menyelesaikan tugas yang banyak.

Berdasarkan beberapa hasil penelitian kondisi ini pernah mendapatkan kajian serius di dunia pendidikan. Penelitian Vaezi \& Fallah (2011) menunjukkan bahwa meningkatkan self-efficacy guru cenderung memiliki pengaruh positif untuk mengurangi stres mereka. Ini pada gilirannya dapat mengarah pada perbaikan kesejahteraan guru, prososial, perilaku, motivasi, dan efektifitas pengajaran dan prestasi siswa yang sesuai. Pada penelitian lain yang dilakukan oleh Rusdi (2015) yang mengatakan bahwa terdapat hubungan negatif dan signifikan antara self-efficacy dengan stres, terdapat hubungan negatif dan signifikan antara manajemen waktu dengan stres dan terdapat hubungan negatif dan signifikan antara self-efficacy dan manajemen waktu terhadap stres, sehingga disimpulkan semakin tinggi self-efficacy dan manajemen waktu, maka semakin rendah tingkat stres mahasiswa. Sebaliknya, semakin rendah self-efficacy dan manajemen waktu, maka semakin tinggi tingkat stres mahasiswa.

Pada penelitian Permatasari \& Arianti (2015) menyimpulkan bahwa ada hubungan negatif yang signifikan antara self-efficacy dengan stres kerja pada relawan PMI di Kabupaten Boyolali. Dengan demikian, dapat disimpulkan bahwa terdapat hubungan antara self-efficacy dengan stres kerja, artinya semakin tinggi self-efficacy pada seseorang maka ia akan mendapatkan stres kerja yang minimum. Begitu juga sebaliknya, jika self-efficacy seseorang rendah maka seseorang tersebut mengalami stres kerja.

Fenomena ini menarik bagi peneliti mengingat pentingnya peran guru sebagai agen yang turut mempengaruhi hasil belajar siswa. Guru diharapkan memiliki stres yang rendah sehingga bisa optimal dalam mendidik. Dalam hal ini peneliti berupaya untuk mencari tahu apakah self-efficacy sebagai aspek internal individu dapat mempengaruhi tingkat stres. Dengan self-efficacy atau keyakinan guru terhadap kemampuannya dalam melakukan tugasnya akan dapat mempengaruhi tingkat stresnya. 
Self-Efficacy :

1. Dimensi Tingkat (level)

2. Dimensi Kekuatan (strength)

3. Dimensi Generalisasi (generality)

\section{Stres Kerja :}

1. Gejala Fisiologis

2. Gejala Psikologis

3. Gejala Perilaku

Gambar 1: Kerangka Konseptual Hubungan Antara Self-Efficacy dengan Stres Kerja Guru SD Negeri.

\section{Metode Penelitian}

Metode yang digunakan dalam penelitian ini yaitu menggunakan pendekatan kuantitatif yang bersifat korelasional, yang bertujuan untuk membandingkan hasil pengukuran dua variabel yang berbeda agar dapat menentukan tingkat hubungan antara self-efficacy dengan stres kerja (Arifin, 2008:131). Populasi yang digunakan dalam penelitian ini adalah Guru SD Negeri di Kecamatan Menganti yang aktif mengajar sebanyak 386 Guru SD. Berdasarkan tabel pengambilan sampel yang dikemukakan oleh Isaac dan Michael, sampel yang akan digunakan oleh peneliti sebesar 186 Guru SD. Teknik sampling yang akan digunakan dalam penelitian ini yaitu teknik cluster sampling sebanyak 186 Guru SD Negeri di kecamatan Menganti.

Teknik pengumpulan data dalam penelitian ini menggunakan 2 skala dengan format skala Likert, yaitu skala self-efficacy yang disusun Dr. James dan E. Maddux yang sudah diadaptasi oleh Suharsono \& Istiqomah (2014:2301-8267) berdasarkan konsep teori tiga dimensi dari Bandura (Gufron \& Risnawita, 2014:80) dan skala stres kerja yang disusun oleh peneliti berdasarkan konsep teori tiga kategori gejala-gejala stres (Robbins \& Judge, 2017:434-435).

Uji validitas pada penelitian ini menggunakan validitas isi yang bertujuan untuk mengetahui ketepatan suatu alat ukur agar dapat mengungkap trait yang akan diukur. Validitas isi yang akan digunakan yaitu validitas logik yang menunjukkan pada kesesuaian tes terhadap indikator dari atribut yang akan diukur sesuai dengan ketetapan dari kawasan ukurnya (Azwar, 2015:42). Suatu item dapat dikatakan valid apabila mencapai koefisien korelasi minimal sebesar 0,30 yang dianggap memuaskan, sedangkan item yang berada pada koefisien korelasi < 0,30 maka item tersebut dianggap tidak memuaskan (Sugiyono, 2015:125). Dari hasil uji validitas pada skala self-efficacy diperoleh dari 21 item terdapat 19 item yang valid dan item yang gugur sebanyak 2 item yaitu item nomor 12 dan 13 . Sedangkan pada skala stres kerja diperoleh dari 46 item terdapat 43 item yang valid dan item yang gugur sebanyak 3 item yaitu item nomor 10, 24 dan 4. 
Pada penelitian ini jenis reliabilitas yang digunakan yaitu koefisien Alpha Cronbach. Perhitungan reliabilitas dalam penelitian ini dilakukan menggunakan program SPSS 16.0 for Windows. Dari hasil uji reliabilitas pada skala self-efficacy diperoleh sebesar 0,766. Sedangkan pada skala stres kerja diperoleh sebesar 0,882 .

\section{Hasil Penelitian dan Pembahasan}

Dari hasil uji normalitas dalam penelitian ini yang dilakukan perhitungan mengguakan Kolmogorov-Smirnov dengan bantuan program SPSS 16.0 for Windows diperoleh angka probabilitas sebesar 0,000 untuk variabel self-efficacy dan 0,015 untuk variabel stress kerja. Hal ini dapat diketahui bahwa hasil data yang diperoleh dari variabel self-efficacy dan stres kerja tidak berdistribusi normal, sehingga analisis data dalam penelitian ini menggunakan statistic non parametrik. Dalam menganalisis data dalam penelitian ini menggunakan analisis Korelasi Sperman Rank dengan bantuan program SPSS 16.0 for Windows.

\section{Tabel 1. Hasil Uji Korelasi}

\section{Correlations}

\begin{tabular}{cllrr} 
& & Self_Efficacy & Stres_Kerja \\
\hline Spearman's rho Self_Efficacy & Correlation & 1.000 & -.127 \\
& & Coefficient & & .288 \\
& Sig. (2-tailed) & 186 & 186 \\
& N & -.127 & 1.000 \\
\multirow{2}{*}{ Stres_Kerja } & Correlation & .288 & \\
& & Coefficient & 186 & 186 \\
\hline & Sig. (2-tailed) & & \\
& $\mathrm{N}$ & & \\
\hline
\end{tabular}

Hasil analisis data korelasi Spearman Rank menunjukkan nilai rho $=-0,127$ dengan $\mathrm{p}=0,288$, artinya tidak sig. (2-tailed) yang berarti koefisien korelasinya tidak signifikan karena nilai sig. pada tabel diatas lebih besar dari 0,05 ( $\mathrm{p}>0,05)$. Sehingga tidak ada hubungan antara self-efficacy dengan stres kerja pada Guru, yang artinya hipotesis nol (H0) diterima sedangkan hipotesis alternatif (Ha) ditolak. Hal ini sejalan dengan pendapat Wallace (Wijono, 2015:176) yang mengatakan bahwa seorang yang tidak mengalami stres kerja adalah seseorang yang merasa bangga akan pekerjaannya, keterlibatan dalam anggota kelompok kerjanya dan memiliki prioritas kegiatan dalam bekerja berdasarkan kebutuhan dan kepentingannya untuk mencapai tujuan yang jelas.

Koefisien determinansi $\left(\mathrm{rho}^{2}\right)$ dari nilai rho $=-0,127^{2}=0,0161$. Artinya rho ${ }^{2}$ $=0,0161$ (berarti 1,61\%) menginformasikan bahwa sumbangan variabel selfefficacy dengan stres kerja pada Guru SD sebesar 1,61\%. Sedangkan sisanya 
98,39\% dipengaruhi oleh variabel lain. Kemungkinan variabel lain yang belum diteliti yaitu kondisi ditempat kerja, tanggungjawab kerja, dukungan sosial dan lain sebagainya. Hal ini didukung oleh Smith (Wijono, 2015:142-144) yang mengatakan bahwa faktor yang mempengaruhi stres kerja yaitu hasil dari keadaan di tempat kerja, faktor organisasi yang meliputi keterlibatan dalam tugas dan dukungan sosial, tanggung jawab kerja, waktu kerja yang berlebihan, dan terdapat tantangan yang muncul dari suatu tugas.

Hal ini senada juga dengan penelitian Soewondo pada tahun 1992 (Wijono, 2015:149) yang menyatakan bahwa faktor yang mempengaruhi stres kerja adalah batas waktu, tekanan waktu, kondisi di tempat kerja, beban kerja, kenaikan pangkat tertahan, hubungan interpersonal ditempat kerja, kurang terbuka antara atasan dengan bawahan, dan ketidakjelasan peran. Berdasarkan hasil wawancara pada tanggal 07 Juni 2018, subjek A mengatakan bahwa beliau menerima semua pekerjaan dan tanggung jawab sebagai guru. Subjek A mengaku bahwa hal itu wajib yang harus diterimanya. Baginya menjadi seorang guru merupakan citacitanya sejak kecil untuk mengajar. Selama mengajar di SD dianggap sebagai hiburan dalam kegiatan sehari-hari. Hal yang membuatnya kesal adalah ketika siswa tidak mendengarkan penjelasan yang diberikannya. Hal ini didukung oleh Robin (Robbin \& Judge, 2017:432) yang mengatakan bahwa keberfungsian dari suatu peran yang dipegang dalam suatu lembaga. Artinya peran yang didapatkan dalam lingkungan kerja merupakan tanggungjawab yang harus dijalankan.

Hal ini juga didukung oleh Munandar (2014:380) yang mengatakan bahwa setiap tenaga kerja bekerja sesuai dengan perannya dalam menjalankan tugasnya, sesuai dengan tugas-tugas yang diberikan dalam suatu organisasi. Akan tetapi, pada saat menjalankan tugasnya setiap tenaga kerja tidak selalu berhasil dalam memainkan peranya tanpa menimbulkan masalah salah satunya yaitu pertentangan dengan nilai-nilai dan keyakinan pribadinya sewaktu melakukan tugas pekerjaan.

Sedangkan hasil wawancara pada tanggal 08 Juni 2018 subjek B mengatakan bahwa selama mengajar sebagai Guru SD, beliau menerima semua pekerjaan dan tanggungjawabnya dengan ikhlas. Beliau menganggap bahwa semua pekerjaan dan tanggung jawab yang diberikan dapat memotivasi dirinya agar lebih semangat dalam menjalankan tugasnya. Hal ini didukung oleh Quick dan Quick (Waluyo, 2013:92) yang mengatakan bahwa salah satu jenis stres yaitu Eustres. Eustress adalah hasil dari respon seseorang terhadap stres yang bersifat sehat, positif dan bersifat membangun (konstruktif). Hal ini termasuk kesejahteraan individu dengan suatu organisasi yang diasosiasikan secara fleksibel, kemampuan beradaptasi dan tingkat performance yang tinggi. 


\section{Kesimpulan}

Berdasarkan data hasil penelitian, dapat disimpulkan bahwa antara selfefficacy dengan stres kerja tidak ada hubungan dengan nilai signifikansi $p=0,288$ artinya nilai $\mathrm{p}>0,05$ sehingga $\mathrm{Ha}$ (Hipotesis alternatif) ditolak sedangkan $\mathrm{H} 0$ (Hipotesis nol) diterima. Artinya semakin tinggi self-efficacy, maka belum tentu stres kerja semakin rendah. Begitu juga sebaliknya, semakin rendah self-efficacy maka belum tentu mengalami stres kerja. Hubungan antara self-efficacy dengan stres kerja pada Guru SD Negeri di Kecamatan Menganti hanya 1,61\% sedangkan 98,39\% dipengaruhi oleh variabel lainnya. Berdasarkan hasil analisis penelitian terhadap variabel self efficacy dengan stres kerja diperoleh data bahwa Guru SD Negeri di Kecamatan Menganti memiliki self-efficacy dan stres kerja yang tergolong sedang. Bagi peneliti yang akan melakukan penelitian menggunakan variabel stres kerja atau self-efficacy diharapkan untuk menambahkan jumlah populasi dan sampel yang lebih luas sehingga hasil penelitian tersebut dapat digeneralisasikan dan dapat menambahkan variabel lain yang mempengaruhi kedua variabel tersebut seperti prestasi kerja, kecerdasan emosional, regulasi diri dan burnout.

\section{Daftar Pustaka}

Arifin, Z. (2008). Metodologi Penelitian Pendidikan Filosofi, Teori \& Aplikasinya. Surabaya: Lentera Cendikia.

Azwar, S. (2015). Reliabilitas dan Validitas. Yogyakarta: Pustaka Pelajar.

Gufron \& Risnawita. (2014). Teori-Teori Psikologi. Yogjakarta: Ar-Ruzz Media.

Handoko, H. (2014). Manajemen Personalia \& Sumberdata Manusia. Yogyakarta: BPFE-Yogyakarta.

Munandar, A. S. (2014). Psikologi Industri dan Organisasi. Jakarta: UI-Press.

Robbins, S. P., \& Judge, T. A. (2017). Perilaku Organisasi. Jakarta: Salemba Empat.

Rusdi, R. (2015). Hubungan antara efikasi diri dan manajemen waktu terhadap stres mahasiswa farmasi semester IV Universitas Mulawarman. Ejournal Psikologi, (Online), Vol. 1 No. 4: hlm. 53-64, (http://ejournal.psikologi.fisip-unmul.ac.id), diakses 5 November 2017.

Sugiyono. (2015). Metode Penelitian Kuantitatif, Kualitatif dan R\&D. Bandung: Alfabeta.

Saragih, H. (2008). Kompetensi Minimal Seorang Gury Dalam Mengajar. Jurnal Tabularasa PPS UNIMED, Vol. 05 No. 01: 23-34. 
Suharsono, Y \& Istiqomah. (2014). Validitas dan Reliabilitas Skala Sef-Efficacy. Jurnal Ilmiah Ilmu Terapan, (Online), Vol. 02 No. 01: 2301-8267. (http://ejournal.umm.ac.id/index.php/jipt/article/view/1776/1864), diakses 22 Mei 2018.

Vaezi \& Fallah. (2011). The Relationship between Self-efficacy and Stress among Iranian EFL Teachers. Journal of Language Teaching and Research. (Online), Vol. 2 No. 5, pp.1168-1174DOI:10.4304/jltr.2.5, (https://pdfs.semanticscholar.org/4432/71bccfb592f052dc9ef57ccf01991d 2f5c98.pdf), diakses 25 November 2017.

Waluyo, M. (2013). Psikologi Industri. Jakarta: Akademia.

Wardani, dkk. (2014). Perspektif Pendidikan SD (S. Nurhayanti, Ed). Jakarta: Universitas Terbuka.

Wijono, S. (2010). Psikologi Industri dan Organisasi. Jakarta: Kencana. 